\title{
Molecular signatures in protein sequences that are characteristic of cyanobacteria and plastid homologues
}

Correspondence

Radhey S. Gupta

gupta@mcmaster.ca

\author{
Radhey S. Gupta, Mark Pereira, Charu Chandrasekera \\ and Vanessa Johari \\ Department of Biochemistry, McMaster University, Hamilton, Ontario, Canada L8N 3Z5
}

Fourteen conserved indels (i.e. inserts or deletions) have been identified in 10 widely distributed proteins that appear to be characteristic of cyanobacterial species and are not found in any other group of bacteria. These signatures include three inserts of 6,7 and 28 aa in the DNA helicase II (UvrD) protein, an 18-21 aa insert in DNA polymerase I, a 14 aa insert in the enzyme ADP-glucose pyrophosphorylase, a 3 aa insert in the $\mathrm{FtsH}$ protein, an 11-13 aa insert in phytoene synthase, a 5 aa insert in elongation factor-Tu, two deletions of 2 and 7 aa in ribosomal S1 protein, a 2 aa insert in the SecA protein, a 1 aa deletion and a 6 aa insert in the enzyme inosine-5'-monophosphate dehydrogenase and a 1 aa deletion in the major sigma factor. These signatures, which are flanked by conserved regions, provide molecular markers for distinguishing cyanobacterial taxa from all other bacteria and they should prove helpful in the identification of cyanobacterial species, simply on the basis of the presence or absence of these markers in the corresponding proteins. The signatures in six of these proteins ( $\mathrm{SecA}$, elongation factor-Tu, ADP-glucose pyrophosphorylase, phytoene synthase, $\mathrm{FtsH}$ and ribosomal $\mathrm{S} 1$ protein) are also commonly present in plastid homologues from plants and algae (chlorophytes, chromophytes and rhodophytes), indicating their specific relationship to cyanobacteria and supporting their endosymbiotic origin from these bacteria. In phylogenetic trees based on a number of these proteins (SecA, UvrD, DNA polymerase I, elongation factor-Tu) that were investigated, the available cyanobacterial homologues grouped together with high affinity ( $>95 \%$ bootstrap value), supporting the view that the cyanobacterial phylum is monophyletic and that the identified signatures were introduced in a common ancestor of this group.

\section{INTRODUCTION}

The cyanobacteria constitute one of the main phyla within the Bacteria: more than 1500 species are known (Kondratieva et al., 1992; Castenholz, 2001). They comprise the sole prokaryotic group capable of oxygenic photosynthesis, and their emergence was a major evolutionary event that changed the Earth's atmosphere from an anoxygenic one to an oxygenic one (Woese, 1987; Kondratieva et al., 1992; Bryant, 1994; Castenholz, 2001). The cyanobacteria, through endosymbiosis, are also believed to be the

Published online ahead of print on 23 May 2003 as DOI 10.1099/ ijs.0.02720-0.

Abbreviations: ADP-Glc-PPase, ADP-glucose pyrophosphorylase; EFTu, elongation factor-Tu; Pol I, DNA polymerase I.

Partial sequence alignments of UvrD, EF-Tu, ribosomal S1 protein, inosine-5'-monophosphate dehydrogenase, $\sigma^{70}$ and $\mathrm{FtsH}$ showing indels characteristic of cyanobacteria are available as supplementary data in IJSEM Online. progenitors of plastids in eukaryotic cells (Giovannoni et al., 1988; Gray, 1992; Morden et al., 1992; Margulis, 1993; Whatley, 1993).

Cyanobacteria exhibit enormous diversity in terms of their morphology, physiology and differentiation characteristics, which has led to the proposal of their division into five subsections (Rippka et al., 1979; Trüper, 1987; Kondratieva et al., 1992; Bryant, 1994; Castenholz, 2001). However, phylogenetic trees based on $16 \mathrm{~S}$ rRNA provide the primary means for the identification and assignment of novel species to this group (Woese, 1987; Honda et al., 1999; Turner et al., 1999; Wilmotte \& Herdman, 2001). Although cyanobacteria form a monophyletic group in $16 \mathrm{~S}$ rRNA trees, the branching of different species within this phylum is found to be highly variable, and different subsections identified on the basis of morphological characteristics are generally not distinguished (Honda et al., 1999; Wilmotte \& Herdman, 2001). Other than phylogenetic trees based on 16S rRNA or various proteins (Viale et al., 1994; Eisen, 1995; Delwiche 
et al., 1995; Gupta et al., 1997; Gruber \& Bryant, 1997), no unique molecular signatures are presently known that can clearly distinguish cyanobacteria from all other bacteria (Castenholz, 2001).

We have recently described a new approach, based on conserved indels (i.e. inserts or deletions) found in various proteins, for identifying different groups of bacteria and for clarifying their interrelationships (Gupta, 1998). The signatures that have been identified are of two kinds. One type of signature, which we refer to as the 'main line' signatures, are shared by several major groups of bacteria but absent from the other bacterial phyla (Gupta, 1998). We have proposed that these signatures were introduced at critical branch points during the course of bacterial evolution, and that they provide useful information for deducing the branching order and interrelationships among different groups of bacteria (Gupta, 1998, 2001). On the basis of different main line signatures, the cyanobacterial phylum is indicated to have evolved after the divergence of various Gram-positive phyla (Firmicutes, Actinobacteria, clostridia and relatives), the Deinococcus-Thermus group and green non-sulfur bacteria, but before the emergence of spirochaetes, the chlamydiae-CFBG (CytophagaFlavobacterium-Bacteroides and green sulfur bacteria) group, Aquifex and different divisions of the Proteobacteria (Gupta, 1998, 2001, 2002, 2003; Gupta \& Griffiths, 2002). The second type of signature is specific for particular groups of bacteria and was probably introduced when these groups or phyla evolved (Gupta, 1998; Griffiths \& Gupta, 2002). Such signatures have been identified for the chlamydiae, Proteobacteria, spirochaetes, Firmicutes and Actinobacteria (Gupta, 1998; Griffiths \& Gupta, 2002; Morse et al., 2002; R. S. Gupta, unpublished results) and they should prove very useful in identifying different bacterial groups in clear molecular terms (Gupta, 2002; Griffiths \& Gupta, 2002).

In this communication, we describe 14 conserved indels in 10 broadly distributed proteins that are specific for cyanobacteria (and, in many cases, also commonly shared by plastid homologues) but not found in any other bacteria. These signatures provide evidence that the cyanobacteria lineage is monophyletic and furnish further evidence for the derivation of plastids from this group of bacteria. Because of their observed specificity, these signatures should prove useful for the identification of cyanobacterial species and for studies on the origin of plastids.

\section{METHODS}

Signature sequences in protein alignments. Multiple sequence alignments for a large number of proteins were created in our earlier work (Gupta, 1998; Gupta, 2000; Griffiths \& Gupta, 2002). To search for signature sequences that might be specific for cyanobacteria, these alignments were visually examined to identify those indels that were unique to the cyanobacterial homologues and were flanked by conserved sequences. The potential usefulness of any such indel was examined by carrying out additional BLAST searches on short sequence segments (usually between 60 and 100 aa long) containing the indel and the flanking conserved regions. The purpose of these BLAST searches was to obtain sequence information from all available species. In most cases, two different BLAST searches were carried out, one with a sequence containing the indel and the other with a sequence that lacked the indel. Indels that were unique to particular cyanobacterial species were not investigated any further. However, for those indels that were commonly present in various cyanobacteria, sequence information from different species was compiled into signature files such as those shown here.

Phylogenetic analysis. Phylogenetic analyses of protein sequences were carried out as described previously (Gupta et al., 1997). A multiple alignment of sequences from different groups of bacteria (and also plastid homologues, where found) was created using the ALIGN program. Any sequence region for which the alignment was deemed unreliable was omitted from phylogenetic analysis. The indel regions were also excluded from the alignment for this purpose. Neighbourjoining distance trees showing branch lengths were constructed using the programs PROTDIST, NEIGHBOR and DRAWTREE. The aligned sequences were also bootstrapped 100 times using the SEQBOOT program, and a consensus neighbour-joining tree based on these data was obtained using the programs PROTDIST, NEIGHBOR and CONSENSE. Bootstrap scores for different nodes that were $>50$ were noted on the trees. All phylogenetic programs used are part of PHYLIP version 3.5 (Felsenstein, 1994).

\section{RESULTS}

\section{Description of indels that are specific to cyanobacteria and plastids}

Conserved indels that are commonly shared by members of one or more taxon provide a powerful means for defining various taxa in molecular terms and for clarifying how they may be related. The indels that have proved useful for evolutionary studies are generally of defined size and present in the sequence at specific locations. They are also flanked by conserved regions, to ensure that they are not due to improper alignment or sequencing errors. We have identified many conserved indels in protein sequences that are characteristic of cyanobacterial species. The descriptions of these indels and their evolutionary significance are reported below.

The SecA protein is found in all sequenced bacterial genomes and is involved in the export of proteins to the periplasmic compartment (Valentin, 1997; Schmidt \& Kiser, 1999). In this protein, we have identified a 2 aa insert in a highly conserved region that is specific to cyanobacteria (Fig. 1). Sequence information for SecA is available from a large number of cyanobacteria. The identified insert is present in all known cyanobacterial homologues, but not in any other bacteria. Interestingly, this insert is also present in SecA homologues from different plastids. Plastid lineages from which sequence information is available include the Chlorophyta (land plants), the Rhodophyta (red algae), the Chromophyta (brown algae) and the Cryptomonadida (Guillardia theta). These results indicate that this insert is a distinguishing characteristic of these groups and that they are specifically related to each other. 


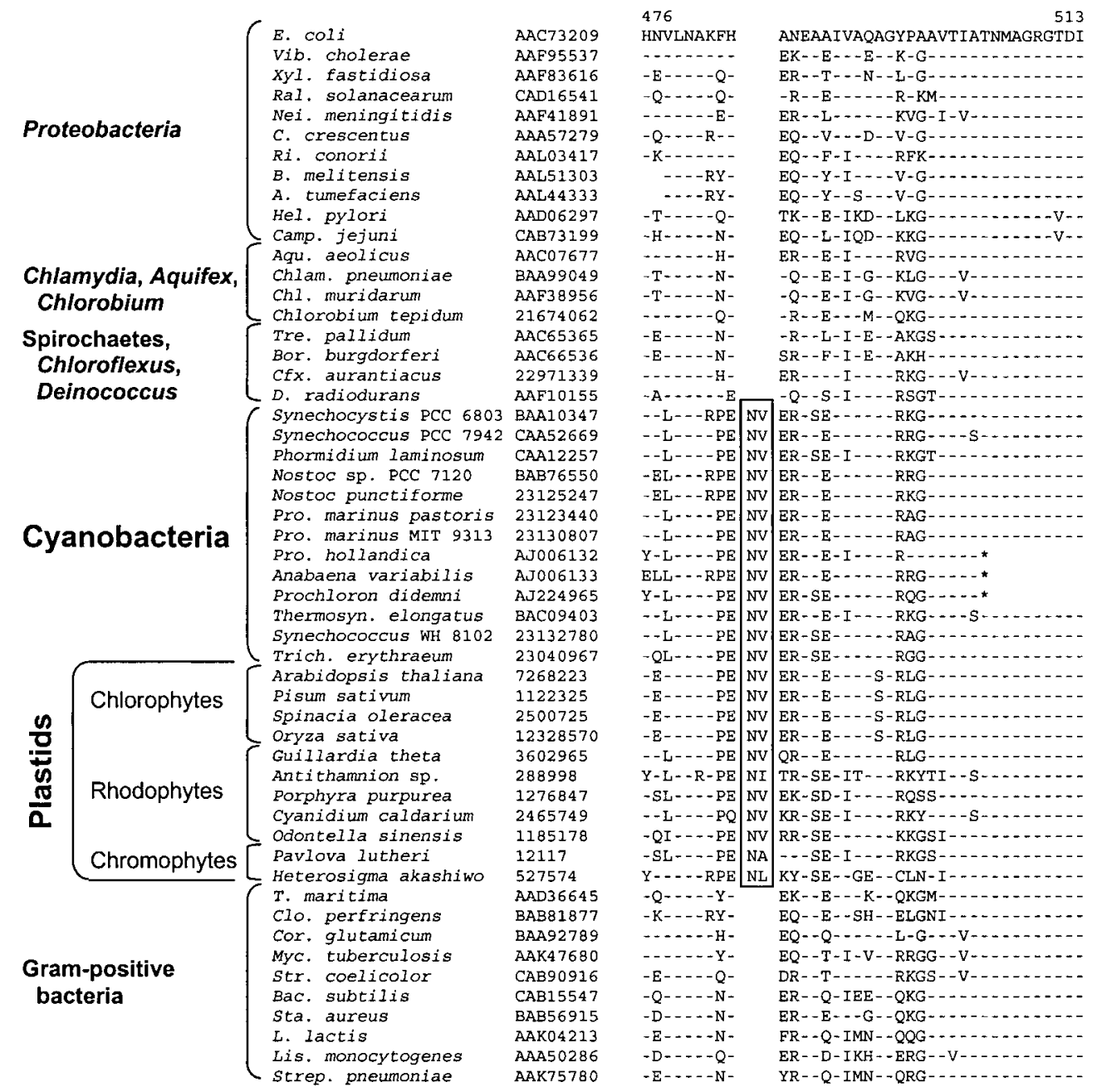

Fig. 1. Partial sequence alignment for SecA protein, showing a 2 aa insert (boxed) in a highly conserved region that is unique to cyanobacterial and plastid homologues and is not found in any other bacteria. Dashes in the alignment indicate residues identical to those on the top line (Escherichia coli protein). The position of this sequence in the $E$. coli protein is indicated at the top. Accession numbers of proteins are given in the second column. The SecA protein is present in all bacterial genomes, and sequence information for only representative species from major bacterial and plastid groups is presented here. Sequences ending in an asterisk are partial. Genera are abbreviated as: A., Agrobacterium; Aqu., Aquifex; Bac., Bacillus; Bor., Borrelia; B., Brucella; C., Caulobacter; Camp., Campylobacter; Cfx., Chloroflexus; Chl., Chlamydia; Chlam., Chlamydophila; Clo., Clostridium; Cor., Corynebacterium; D., Deinococcus; E., Escherichia; Hel., Helicobacter; L., Lactococcus; Lis., Listeria; Myc., Mycobacterium; Nei., Neisseria; Pro., Prochlorococcus; Ral., Ralstonia; Ri., Rickettsia; Sta., Staphylococcus; Str., Streptomyces; Strep., Streptococcus; T., Thermotoga; Thermosyn., Thermosynechococcus; Tre., Treponema; Trich., Trichodesmium; Vib., Vibrio; Xyl., Xylella.

We have also performed a phylogenetic analysis based on SecA sequences. Earlier phylogenetic studies on SecA have contained only a limited number of sequences from cyanobacteria and other bacteria (Valentin, 1997; Barbrook et al., 1998). Fig. 2 shows a neighbour-joining tree with branch lengths for SecA sequences. The bootstrap scores for various nodes that were $>50$ are also noted. As seen from their bootstrap scores, most of the bacterial groups in this tree are well resolved from each other. However, their relative branching order is not resolved, which is a common problem in phylogenetic trees (Gupta, 1998; Ludwig \& Klenk, 2001). In the SecA tree, all cyanobacteria and plastid homologues formed a well-defined clade (100\% bootstrap score), supporting the inference of the identified signature that these groups shared a common ancestor exclusive of other bacteria. Within this clade, the sequences corresponding to cyanobacteria were clearly resolved from those of the Chlorophyta and the Rhodophyta-Chromophyta. An unusual aspect of this tree, which has also been noted in earlier studies (Valentin, 1997; Barbrook et al., 1998), is that 


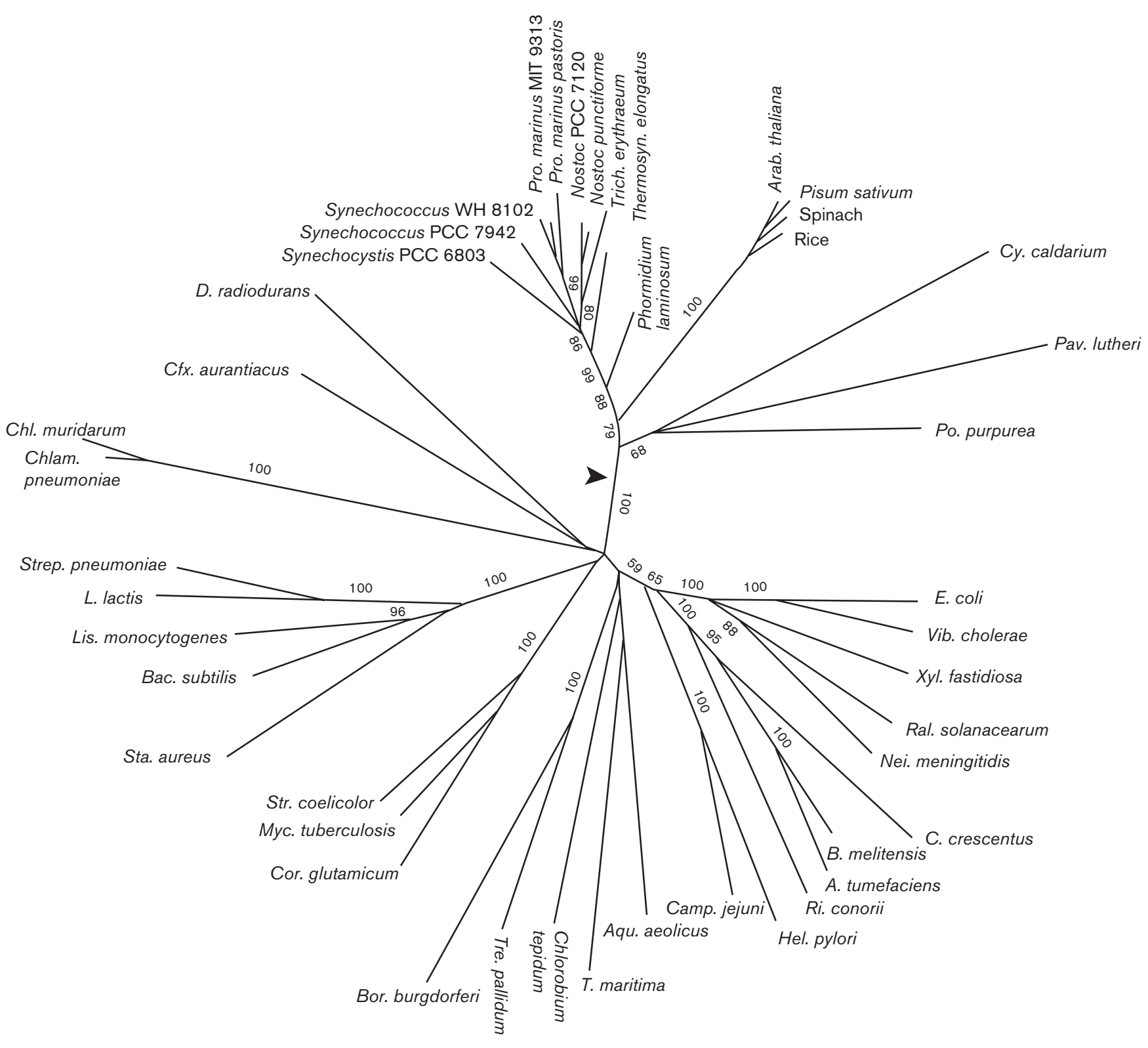

Fig. 2. Neighbour-joining distance tree with branch lengths based on SecA protein sequences. The tree is based on 516 aa positions that could be aligned without any ambiguity. The insert region was not included in the alignment. Bootstrap scores (out of 100) of various nodes that were $>50$ are indicated. Genus name abbreviations are listed in the legend to Fig. 1. Additional abbreviations: Arab., Arabidopsis; Cy., Cyanidium; Pav., Pavlova; Po., Porphyra. The arrowhead marks the suggested stage at which the insert identified in this protein was introduced.

the plastid homologues branched more deeply than the cyanobacteria. This is an unexpected result if plastids have been derived from cyanobacteria. However, as seen in Fig. 2, in comparison with cyanobacteria, all of the plastid sequences have much longer branch lengths, indicating that they have been evolving at a faster rate. The deeper branching of the plastid lineages in SecA phylogenetic trees, therefore, is very probably a consequence of the long branch-length effect, which leads to a deeper and abnormal branching of faster-evolving taxa (Felsenstein, 1978; Barbrook et al., 1998).

In the DNA helicase II (or UvrD) protein, which plays an essential role in the nucleotide excision repair and methyldirected mismatch repair pathways (Eisen \& Hanawalt, 1999), we have identified three cyanobacteria-specific indels. These signatures include a large, 28 aa insert (Fig. 3) as well as two inserts of 6 and 7 aa (see 


\begin{tabular}{|c|c|c|c|c|c|}
\hline & & & 62 & & 104 \\
\hline & E. $\operatorname{col} i$ & 43297 & TFTNKAAAEMRHRIGQLM & & GTSQGGMWVGTFHGLAHRLLR \\
\hline & XYl. fastidiosa & 15836655 & $\ldots-.-$ G-IQQ--DLQL & & RHGKR - I I - . S S . . \\
\hline & Vib. cholerae & 15640220 & 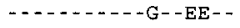 & & HGTAS- - -C- - IC- I I - \\
\hline & Nei. meningitidis & 15793060 & $-----K--Q T-L-A M I$ & & PVNVRA $--\mathrm{L}-\cdots-\mathrm{C}-\mathrm{F}-\mathrm{-}$ \\
\hline & Nit. europaea & 22955362 & $-\ldots---$ RA- - AML & & PVNTRA- - - - - C- - V - \\
\hline Proteobacteria & A. tumefaciens & 5889343 & $-----R--K E---V-V$ & & G-AVE-MP-L- - -SIGVK-.- \\
\hline & B. melitensis & 17986879 & $\cdots-\mathrm{K}-\mathrm{K}-\mathrm{KE}--\mathrm{H}-\mathrm{V}$ & & G-AVE-MP-L--- -SIGVK--- \\
\hline & c. crescentus & 16125775 & $\cdots--R=-E--$ THII & & GPEAE-LR-L---SV-AQI-- \\
\hline & Ri. conorii & 15619709 & $----K--A E-V N S-I$ & & NCY - LNI - - -SM-A-I - \\
\hline & Hel. pylori & 15612436 & --- SK- -QE-ALK-L & & KNQALI I PLLLC- - -RFGLLF - - \\
\hline & Camp. jejuni & 15792115 & $---S K--I G-L-K F F$ & & DKNITSKILA- - -ST-YT-- \\
\hline Chlamydia, & Aqu. aeolicus & 15606167 & $-\cdots-\mathrm{K}-\mathrm{IKE}-\mathrm{KNT}$ & & GLELE-S - - - SV-LKI-K \\
\hline & ChI, muridarum & 15835512 & ..... K-LNE-VLTQC & & NFPDYR-IPM-S - - - S-GVYI - - \\
\hline And & Chlam. preumoniae & 7190013 & $\cdots-$-R-LKE- - VNQC & & ASTNEFDVPM-C $-\cdots$-S-GVFI - - \\
\hline Chlorobium & Chlorobium tepidum & 21673182 & $\cdots-\cdots$ - - Q- DSIL & & EYG-ASSL -I $\ldots$-SVEA $\ldots$ \\
\hline Spirochaetes, & Tre. pallidum & 7436418 & $\cdots-R_{-1}-A C$ AL & & BSAAQ-ATIC---A-GVWI-- \\
\hline & Bor, burgdorferi & 15594689 & $----N--N D--N D-L$ & & KFDKKLHIQ - - SFGSW - - - \\
\hline Cniorotiexus, & Cfx. aurantiacus & 22971001 & $\cdots-R-I-E-L N L-V$ & & GE-VAHEITI - - - AICT-W - - \\
\hline Deinococcus & D. radiodurans & 15806776 & $------E-A-H-V$ & & PGA-DL-MS-- -SAGV-I-- \\
\hline & Thermus thermophilus & 2618592 & $-----E---E-L R G-V$ & & PGA-EV--S-- -AA-L-I-- \\
\hline & Nostoc sp. PCC 7120 & 17231987 & $\cdots--\mathrm{R}-\mathrm{KE}-\mathrm{-QR}-\mathrm{F}$ & AEQLALTEHGKRLDLLPEHEQTKLRSRVY & 'Y \\
\hline & Nostoc punctiforme & 23126742 & $----\mathrm{R}--\mathrm{KE}--\mathrm{QR}-\mathrm{F}$ & - -MKQ-Q- Q - T-YQ-Q- -Q & - KSTIKDL-C- - - S-FS-I - - \\
\hline & Synechococcus WH 8102 & 23132865 & $-----R--K E-L E V-L$ & -QK- -QSQY-QPWST - - PVD-RQ- - - I - & - REVSKEL - I - - -A-FA-M- - \\
\hline & Trich. erythraeum IMS 101 & 23043549 & $-----Q--K D--E K V F$ & -QEQ-EAKYN-PFSA-TSE-IR--Q- - & - KNI TKHL---- - - -CA-I - - \\
\hline vanobacteria & Thermosyn. elongatus BP-1 & 22300001 & $---R--K E=-E T-F$ & SQEM-QQLY-RDWLD-SPA--RRV- - . & - H-YTQPL - I - . - -S-CA - - . \\
\hline & Synechocystis PCC 6803 & 16330097 & $----K--K E-L E K I F$ & -QAW-QQ - FSQ-WE - -GKY - - KQ-L - - - & $-K-V T K P L-I-\cdots-S-C S-I \ldots$ \\
\hline & Pro. marinus MIT 9313 & 23132357 & $\cdots \cdots \mathrm{R}-\cdots \mathrm{KE}-\mathrm{LEL}-\mathrm{L}$ & -QR--QSQF-QPWST - - PV- -RQ- - T- I - & - REVTKEL-I - - A-FA-M - - \\
\hline & Pro. marinus CCM 1375 & 5734491 & $\cdots-R--K D-L E I-L$ & -QK- -KI-F-QPFST-KISI -SE- - T-I - & - REVIKEI -I - - -A-FA- - - \\
\hline & Pro. sp. PAC-1 & 7007365 & $\cdots--R--K D-L E L-L$ & -KR-SSLT-- - PWRA-QVA--REI-N-IH & H $\mid$ REISREL-I - - -A-FS--- \\
\hline & Pro. marinus pastoris & 23122171 & $\cdots--K--K A-L Q V-L$ & -QEI - -NQF-QPWST -K-FD-NQ- -TNID & D QERLRDL $-I-\cdots$ A-FS $-\cdots$ \\
\hline & T. maritima & 4981792 & $--R A--R--V E-A K A V T$ & & -RELSE - LA - . - HVCNHF - - \\
\hline & Clo. perfringens & 18311242 & $\cdots--G---E-V K S-V$ & & -EVANN - - IS - - -SSCV-I - - \\
\hline & Myc, tuberculosis & 15608089 & $--1---E-V V G-V$ & & -EKARY - -S-- -STCV - I - - \\
\hline & Cor. glutamicum & 19552081 & $-\cdots---$ E-VS - - V & & -PVAER --- A -- SVCV $-\mathrm{I}--$ \\
\hline n-posi & str. coelicolor & 21223175 & $------G--K E-V E--V$ & & - PRANA-- -M- - -SACV-I - - \\
\hline bacteria & sta. aureus & 15924895 & $----R--K E-V Q K-V$ & & -DQAEVI -MS - - SMCV-I -- \\
\hline & L. lactis & 12724080 & $-----K--E-A L S-T$ & & PRAQDTLIA---SMCV-I - - \\
\hline & Strep. pneumoniae & 14972562 & $----R--K E-A Y S-N$ & & PATQDCLIA-- -SMCV-I - - \\
\hline & Lis, monocytogenes & 16803799 & $-----R--K S--N--$ & & -GEAESI - IS - - -SMCV - I - - \\
\hline & Bac. subtilis & 16077729 & $\cdots-\mathrm{R}--\mathrm{KE}$-VESIL & & - PGADDI - IS - - SMCV - I - - \\
\hline
\end{tabular}

Fig. 3. Excerpt from a sequence alignment of DNA helicase $\|$ (UvrD) protein showing a 28 aa insert (boxed) that is characteristic of cyanobacteria. The UvrD protein is present in all bacterial genomes, and sequence information for only representative species is presented. Abbreviations of genus names are given in the legend to Fig. 1.

Supplementary Fig. A in IJSEM Online) in conserved regions. UvrD is present in all bacterial genomes, but not in the Archaea or plastids. Since the inserts identified are not found in any other bacteria, they are cyanobacteria-specific. In a phylogenetic tree based on UvrD sequences (excluding the indel regions), all cyanobacterial homologues grouped together with a $100 \%$ bootstrap score (Fig. 4). This result supports the monophyletic nature of the cyanobacterial taxa and provides evidence that the indels identified in this protein were introduced in a common ancestor of this group (see the arrowhead in Fig. 4).

Another prominent cyanobacterial signature consisting of an 18-21 aa insert has been identified in the DNA polymerase I ( $\mathrm{Pol}$ I) protein (Fig. 5). Similarly to UvrD and SecA, Pol I is found in all sequenced bacterial genomes. The insert identified is present in all known cyanobacterial homologues, but not in any other bacteria (Fig. 5). The length of this conserved insert shows some variation in different species, possibly due to further mutations/changes that have occurred in individual species. In a phylogenetic tree based on Pol I sequences, all cyanobacterial species again formed a well-defined clade ( $100 \%$ bootstrap score; results not shown), supporting their monophyly as suggested by the shared signature. The Pol I homologues of eukaryotic species do not contain this insert. However, most of the eukaryotic sequences are for polymerase $\theta$, except possibly that from Oryza sativa, which Kimura et al. (2002) have reported corresponds to a Pol I-like protein and is localized in the plastids.

Two additional cyanobacteria- and plastid-specific signatures are given in Fig. 6 . The first of these signatures is in the enzyme ADP-glucose pyrophosphorylase (ADP-Glc-PPase), which is involved in the synthesis of glycogen in bacteria and starch in plants (Preiss, 1996). The cyanobacterial homologues of this protein contain a 14 aa conserved insert that is not found in any other bacteria (Fig. 6a). In bacteria, the ADP-Glc-PPase is a homotetramer, whereas the plastid enzyme is made up of two small (catalytic) and two large (regulatory) subunits (Preiss, 1996). Interestingly, the signature identified is present in both the large and small subunits of the plastid enzyme, providing evidence that both originated from cyanobacteria. The other cyanobacteriaplastid signature, shown in Fig. 6(b), is in the enzyme phytoene synthase, which plays a key role in the biosynthesis of carotenoids (Armstrong, 1997). The carotenoid pigments play important roles as light-harvesting molecules in photosynthetic reaction centres. The phytoene synthase from various cyanobacteria contains an 11-13 aa insert that is not found in any other bacteria. With the exception of Deinococcus-Thermus, all of the bacterial phyla in which this protein is found contain at least some photosynthetic members (Woese, 1987). The plastid homologues of this 


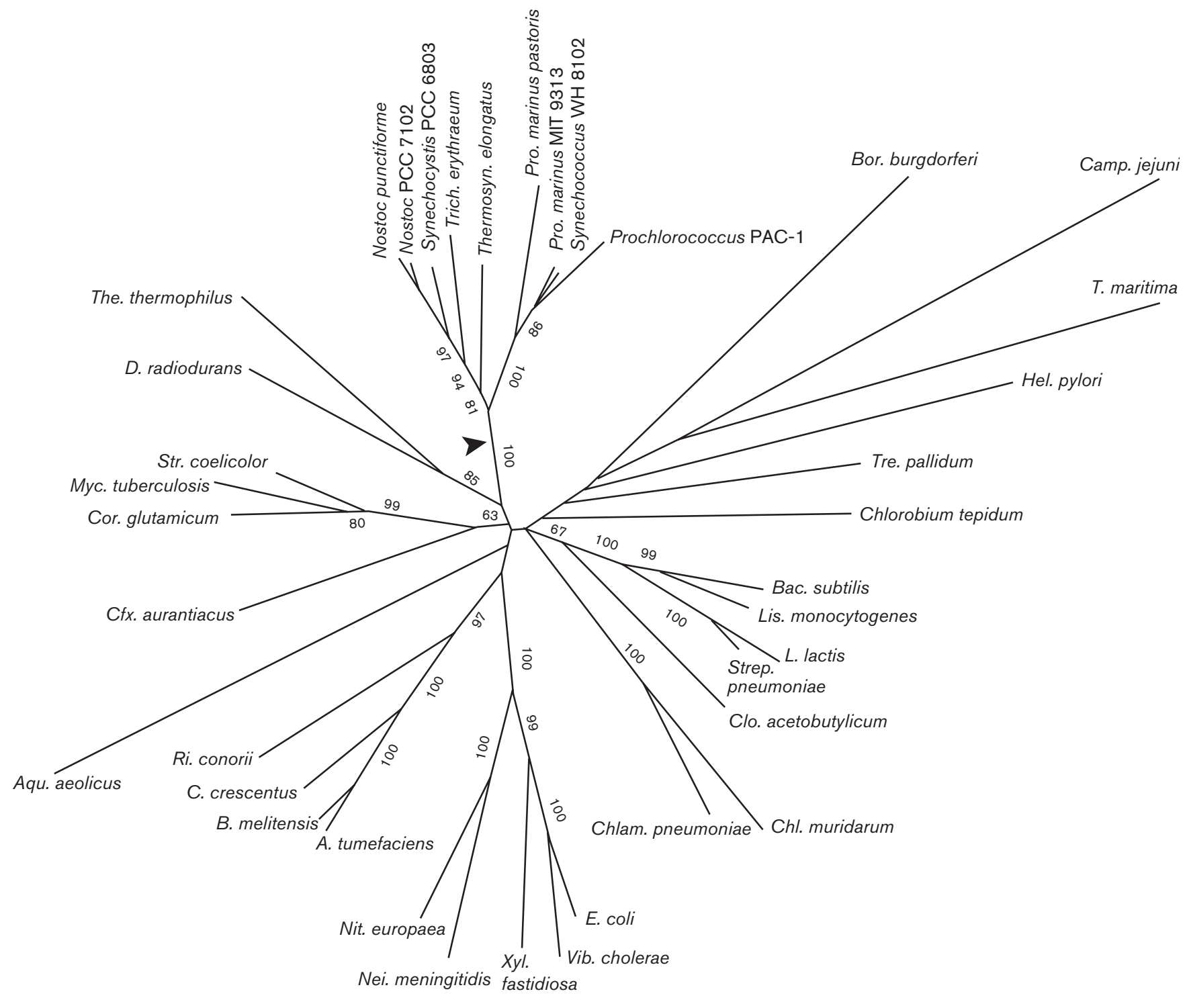

Fig. 4. Neighbour-joining tree with branch lengths based on UvrD protein sequences. The tree is based on 280 aa positions and bootstrap values $>50$ are shown on nodes. The arrowhead marks the position at which the insert in this protein was introduced. Abbreviations of genus names are given in the legend to Fig. 1. Additional abbreviations: Nit., Nitrosomonas; The., Thermus.

protein also contain an insert in the same position (Fig. 6b). However, this insert is shorter than that in cyanobacteria ( 7 aa versus 11 aa), indicating either that it arose independently or that a further deletion occurred in this gene during the evolution of plastids.

We have identified seven other conserved indels that are characteristic of cyanobacteria. Sequence alignments of these signatures are provided as Supplementary Figs B-F in IJSEM Online, and a brief description of them follows. Delwiche et al. (1995) have previously described a 5 aa conserved insert in elongation factor-Tu (EF-Tu) that was present in cyanobacterial and plastid homologues. We have updated the sequence information for this signature (Supplementary Fig. B) and have confirmed its specificity for these groups. Phylogenetic trees based on EF-Tu sequences again support the monophyletic nature of the cyanobacterial phylum and the derivation of plastids from this group of bacteria (Delwiche et al., 1995; R. S. Gupta, unpublished results). Ribosomal S1 protein, which is widely distributed among bacteria (Subramanian, 1983), also contains two signatures ( 2 and 7 aa deletions) that are characteristic of cyanobacteria (Supplementary Fig. C). In contrast to other bacteria, cyanobacteria possess two different S1 protein homologues, both of which contain these signatures, suggesting that they arose from a gene-duplication event 


\begin{tabular}{|c|c|c|}
\hline & Synechocystis PCC 6803 & 16331949 \\
\hline & Nostoc sp. PCC 7120 & 17228749 \\
\hline \multirow{10}{*}{ Cyanobacteria } & Trich. erythraeum & 23040910 \\
\hline & Nostoc punctiforme & 23125316 \\
\hline & Thermosyn. elongatus & 22298882 \\
\hline & Synechococcus WH 8102 & 23133301 \\
\hline & Pro. marinus pastoris & 23122969 \\
\hline & Pro. marinus MIT 9313 & 23131695 \\
\hline & E. $\operatorname{coli} \mathrm{K} 12$ & 16131704 \\
\hline & Vib. cholerae & 15640140 \\
\hline & $X_{Y 1}$, fastidiosa & 15837705 \\
\hline & Ral. solanacearum & 17546949 \\
\hline \multirow{7}{*}{ Proteobacteria } & Nei. meningitidis & 15793464 \\
\hline & B. melitensis & 17988108 \\
\hline & A. tumefaciens & 15887465 \\
\hline & c. crescentus & 16127694 \\
\hline & Ri. conorii & 15893129 \\
\hline & Hel. pylori & 2314647 \\
\hline & Camp. jejuni & 15791706 \\
\hline \multirow{4}{*}{$\begin{array}{l}\text { Chlamydia, } \\
\text { Chlorobium }\end{array}$} & Ch1. trachomatis & 15605221 \\
\hline & Ch1. muridarum & 15835394 \\
\hline & Chlam. pneumoniae & 15618522 \\
\hline & Chlorobium tepidum & 21674485 \\
\hline \multirow{9}{*}{$\begin{array}{l}\text { Spirochaetes, } \\
\text { Chloroflexus, } \\
\text { Deinococcus }\end{array}$} & Bor. burgdorferi & 15594893 \\
\hline & Tre. pallidum & 15639099 \\
\hline & Lep. interrogans & 24216324 \\
\hline & Cfx. aurantiacus & 6015002 \\
\hline & $D$, radiodurans & 15806710 \\
\hline & Thermus thermophilus & 1097211 \\
\hline & T. maritima & 15644367 \\
\hline & Clo. acetobutylicum & 15894383 \\
\hline & Fuso. nucleatum & 19714234 \\
\hline \multirow{9}{*}{$\begin{array}{l}\text { Gram-positive } \\
\text { bacteria }\end{array}$} & Myc. tuberculosis & 15608767 \\
\hline & str. coelicolor & 21220485 \\
\hline & Cor. glutamicum & 19552567 \\
\hline & Sta. aureus & 21283362 \\
\hline & Bac. subtilis & 16079961 \\
\hline & L. lactis & 15674124 \\
\hline & Li. monocytogenes & 16803605 \\
\hline & Strep. pneumoniae & 15899978 \\
\hline & Homo sapiens & 27666712 \\
\hline \multirow[t]{3}{*}{ Eukaryotes } & Mus musculus & 28493899 \\
\hline & Dros. melanos & 2340084 \\
\hline & Arabidopsis thaliana & 3063700 \\
\hline
\end{tabular}

855

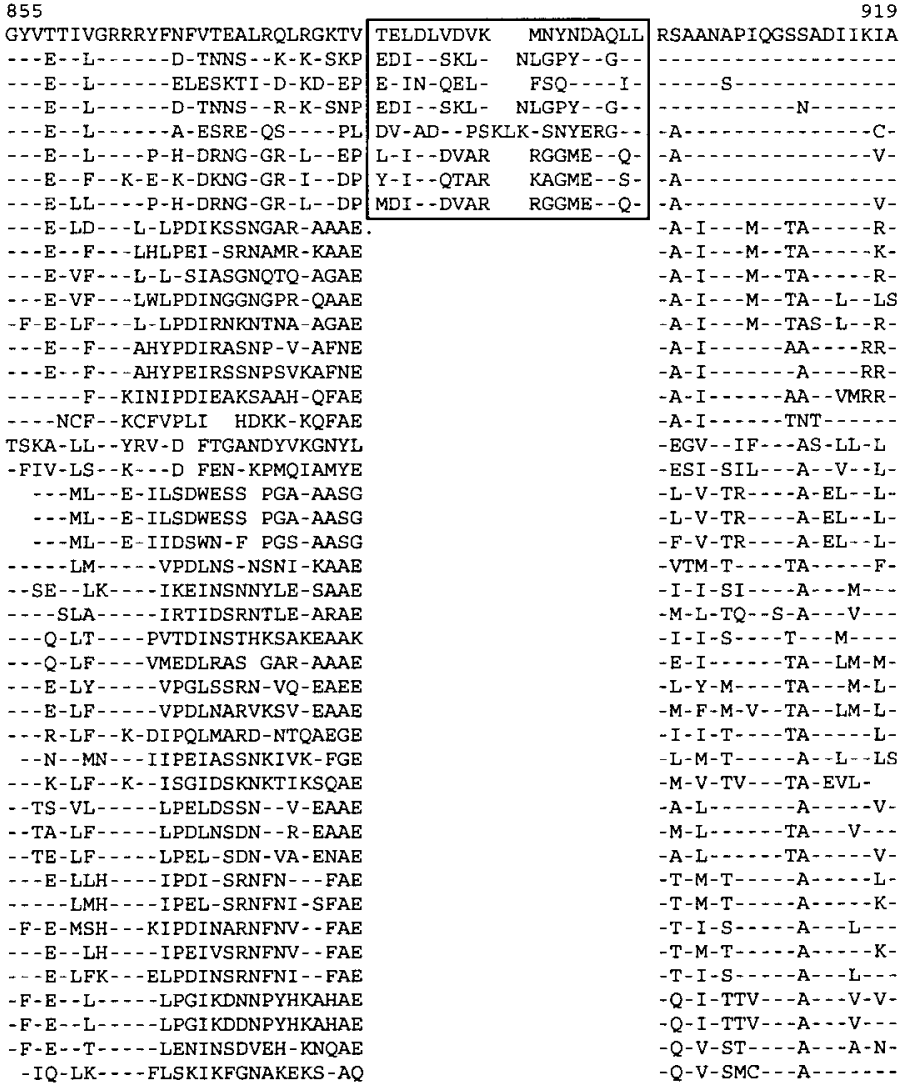

919 : . - 


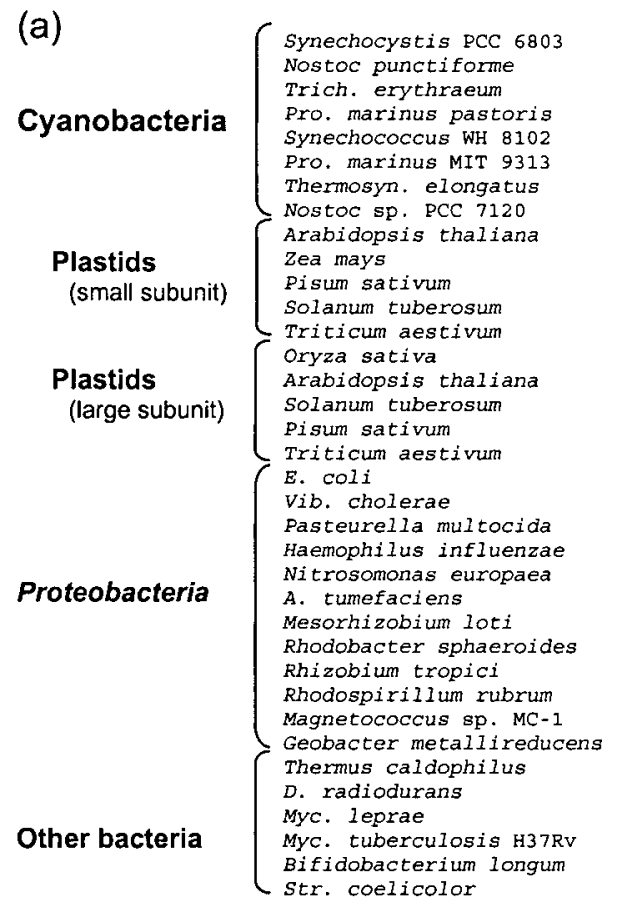

\begin{tabular}{|c|c|c|c|}
\hline & 185 & & 25 \\
\hline 16332282 & FSEKPQGEALRAMQ & VDTSVLGLSAEKAK & LNPYIASMGIYVF \\
\hline 23126438 & $----\mathrm{K}-\cdots$ TQ- & $\cdots-T K-Q-Q$ & KQ \\
\hline 23040615 & $----K-N--K--A$ & $---I-V-P-I-T$ & KQ- $\ldots \ldots$ \\
\hline 23122620 & $---\mathrm{T}-\mathrm{K}-\mathrm{KS}-\mathrm{A}$ & $-\cdots$ KF - TK $-S-S$ & EK- - L - . - . \\
\hline 23133659 & -R-- -K-DS-LE-A & $-\cdots$ RF- - NS - & $E R-L=\ldots$ \\
\hline 23131224 & $-R-\cdots-K--S-K--A$ & $---R F---S-R$ & NK $--\mathrm{L}-\cdots$ \\
\hline 22298830 & $-R---T-D---D-R$ & $\cdots$ TRY - TI -E -H & RK $\cdots \ldots$ \\
\hline 17232137 & $----K---T K-R$ & $-\mathrm{T}-\cdots \mathrm{TP}-\mathrm{Q}-\mathrm{A}$ & sQ $\ldots . .$. \\
\hline 15239684 & $----\mathrm{K}-\mathrm{DD}-\mathrm{K}--\mathrm{A}$ & $\cdots$ TI $\cdots-K-E-E$ & KK--..-- - V-- - \\
\hline 14582768 & $-A---K-D Q-K--M$ & $--T I \cdots-D D-R--$ & EM- - - - - \\
\hline 1237082 & $-A---K--Q-K--K$ & -- TI - -DD-R- & EM-F- - . \\
\hline 21403 & $-A-\cdots-Q-Q--K$ & - - -TI - - DDKR-- & 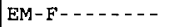 \\
\hline 82597 & $\cdots-K-D D-E--K$ & -- - F-NFAIDDPA & 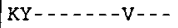 \\
\hline 22831238 & -L- - -KD -S-KS - - & L $-M G T F-$-RP-V-D & TCK $-M-\ldots \ldots$. \\
\hline 25288667 & $----\mathrm{K}-\mathrm{DD}-\mathrm{K}-\cdots$ & $---I--$ PPKE-A & ES-- - - - -V-- \\
\hline 82265 & $-\mathrm{A}-\cdots-\mathrm{K}-\mathrm{FD}-\mathrm{K}---$ & -- TLV -- PQD -- & $\mathrm{KS}-\cdots$ \\
\hline 1619325 & ---- K-ADPK-- - & $\cdots \mathrm{T}-\cdots \mathrm{KDE}-\mathrm{L}$ & EK- - - - - -V - \\
\hline 21677 & $---\mathrm{R}-\mathrm{AD}-\mathrm{KE}-\mathrm{E}$ & $E-E$ & KKP - - - - - V-I \\
\hline 299130 & -V---ANPPSMPND & & PSKSL $\cdots$ \\
\hline 15601455 & -V---ADPPCIPNR & & PDHSL - - - - I - \\
\hline 15602408 & -V-- -KDPPAMVGK & & P-TSL $\ldots$ \\
\hline 16273269 & -V-- -KDPPAMVGK & & PDVSL $\ldots$ \\
\hline 22955853 & -A---EHP-PIPGK & & PGHALI .... \\
\hline 729581 & -I-- -ADPPGIPGN & & EGFAL $\ldots \ldots$ \\
\hline 14279431 & -V-- -ADPPGIPGN & & PEFAL $=\ldots$ \\
\hline 5834406 & -L- - -ADPPGI PGD & & EANAL $\cdots \cdots$ \\
\hline 11493198 & -V-- -ADPPGI PGN & & PDFAL $-\ldots$ \\
\hline 19554293 & $-\mathrm{L}---$ ANPPGI I PGR & & PDRAF - - - I - \\
\hline 22998476 & -L----TPPELPNR & & PGWAL $\ldots . .$. \\
\hline 23055090 & -E-- -ANPVTI I PGR & & ETCF - - - N-I - \\
\hline 2731770 & -Q- - EEPKPIPGR & & PDMAL - - - N-I - \\
\hline 15806692 & -H--VPDPPTIPG- & & ADLSLT-- -N-I- \\
\hline 15827523 & -T---LKPPGTPDD & & PDKTFV- - - N-I - \\
\hline 15608353 & -V- - -LEPPGTPDD & & PDTTFV- - - N-I - \\
\hline 23465440 & -Q-- -PTTTGLPDN & & $\mathrm{P}-\mathrm{QIL} \cdots-\mathrm{N}-$ \\
\hline 21219479 & -L- - -ADPPGL-DD & & PGCVF $\cdots-\mathrm{N}-$ \\
\hline
\end{tabular}

(b)

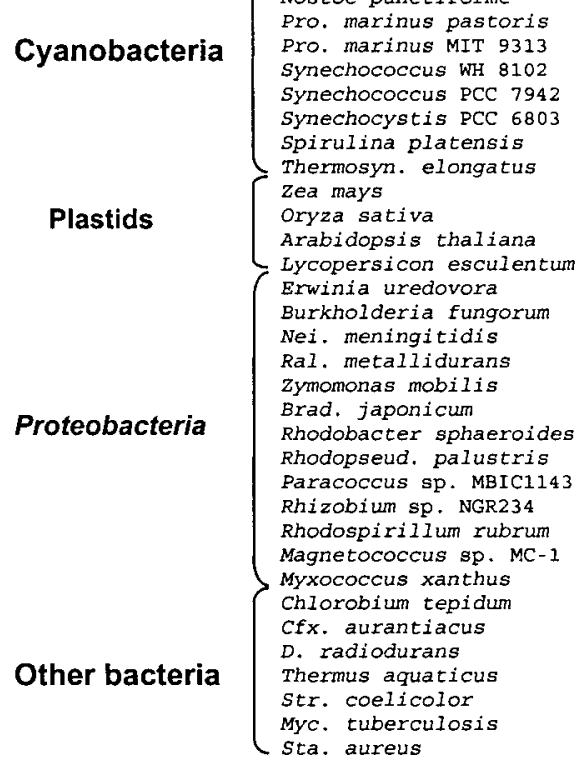

23040328
17229325
23127300
23122018
23132434
23134622
585009
585010
2189955
22299103
1346883
18476089
15810497
19347
117496
22985834
15677007
22975141
4388701
2113821
1075575
22963486
1706137
16519643
22968927
23000914
321671
21674208
22974245
15805888
585011
21225053
1449390
15925552

158

\begin{tabular}{|c|c|c|}
\hline $\begin{array}{l}158 \\
\text { JAGTVGLMTMPVMGIETSNV }\end{array}$ & & $\begin{array}{r}209 \\
\text { JaSEATALGIANOLTNILRD }\end{array}$ \\
\hline $\begin{array}{l}\text { VAGTVGLMTMPUMGIETSNV } \\
--\cdots-- \text { STA }- \text { EVDNTTN }\end{array}$ & $\begin{array}{l}\text { AAPQKSHQQFQY } \\
\text { T - - WHQSKPLYI- }\end{array}$ & 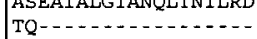 \\
\hline - N & T- -WHQNK-PYL- & TE $\ldots \ldots$ \\
\hline$\cdots-$ QN -1 - DSAYT & S--WS & SES $\ldots \ldots$ \\
\hline$-\cdots-$ QH -- LDPAYT & T--WS & SDA $\ldots \ldots$ \\
\hline - . - - - Q - VDGAYT & s--ws & SDA-V $\ldots \ldots$ \\
\hline - - - - SQ- - - ST -S & R--WDPT TPPD- & TQ - $\mathrm{L} \ldots \ldots$ \\
\hline$\ldots$ SSA-L-VD-G-G & Q--WQPD AVYI- & $\mathrm{QE}-\ldots-\mathrm{V} \ldots$ \\
\hline$-\ldots-$ SLA - - TAEPDL & SV-WNRD-SIY - - & $\mathrm{KE} \cdots$ \\
\hline----- SLE--GDPYSD & RL-WDPY-AKGTL & KDQ $\ldots \ldots$ \\
\hline$-\cdots--$ SV $\cdots--$ A-ESK & -TTESVY & $-A-L-\cdots--$ \\
\hline$------\mathrm{V}---$-APDSK & -STESVY & NA $-\mathrm{L}, \ldots \ldots$ \\
\hline$\cdots-\cdots-$ SV $-\cdots-$ DQKSK & -TTESVY & NA $-\mathrm{L}-\ldots \ldots$ \\
\hline$-\ldots-$ SV-I - -APESK & -TTESVY & NA $-L \ldots \ldots$ \\
\hline - - -V - - -MAQI - - VRDNAT & & LDR -CD- - L-F- - - A - - \\
\hline - -SAA-RLSVRIF - MQDEPG & & RLL-HH- - R-I- - . \\
\hline ---V- -CLIARIL-FSDDQT & & LEY-DKM-L-L----I-- \\
\hline - -SA- -RLAVR-F-LDEAPG & & IAL-HH - - R-L \\
\hline --SA--RLSVY-F-MDPNIG & & $E-L-Y H--R-L-\cdots$ \\
\hline - -SA--RLSVR-F-LPEEDG & & IQL-YH - -R-L- - . \\
\hline$--A A--A-M C V L-R V R D P D-$ & & LAR-CD- - L-M- - - - A - - \\
\hline$\cdots-\mathrm{V}-\mathrm{MTL} \cdots-\mathrm{QRKPDI}$ & & VAR - CD- - C-M- - - -A - - \\
\hline - - - I- -V-MAR-- -VRDDP- & & $L D R-C D-L-F-\cdots-A--$ \\
\hline - -SA- -R-SVR-F-LSEEDG & & IAL $-\mathrm{HH}--\mathrm{R}-\mathrm{L}-\cdots \cdots$ \\
\hline ....-A-MTVL- - VREPA- & & LAR-CD--V-M-F- - A-- \\
\hline -SVA- - AAL - - F - VTGERA & & QQF-HH - - M-L- . . . . . \\
\hline$--\mathrm{V}-\cdots \mathrm{LT}-\mathrm{L}-\mathrm{CSDAAA}$ & & VEP-AD- - R-M- - - \\
\hline - -SV-----VEIF-YSNKEA & & LQH - - D - - M M - - - . \\
\hline - -SV---LVIGIT-AAPGAQ & & $P Y--K--V-L=--$ \\
\hline$--V--F-V A-I S-Y R G G A A$ & & TLND-LQ- -Q-M- - - - \\
\hline$---\mathrm{R}-\mathrm{MA}-\mathrm{IA}-\mathrm{GGKEAE}$ & & $A R-V K=-Q-M-\cdots$ \\
\hline -AI - RLSLG - F- T - PGAR & GAER & APEY - DT - - L-L- - \\
\hline G- - - I-KLCLSIF - PVSTAT & & SRY-EQ - - - L-Q- $-\ldots$ \\
\hline ----EVLT-ILSDHETHQ & & TYDV-RR--ESL- - I - . . \\
\hline
\end{tabular}

Fig. 6. Partial sequence alignments of ADP-Glc-PPase (a) and phytoene synthase (b) showing signatures (boxed) that are characteristic of cyanobacterial and plastid homologues. Plastids have two homologues of ADP-Glc-PPase, both of which contain the insert. The insert in phytoene synthase in plastids is smaller and could have involved a further deletion. Additional abbreviations: Brad., Bradyrhizobium; Rhodopseud., Rhodopseudomonas.

of PCR primers to amplify the sequence region from other bacteria, which will be carried out in future work.

Cyanobacteria are a very diverse group, exhibiting enormous variation in their cell division and morphological characteristics. However, the taxonomic relationships within this phylum are not understood (Rippka et al., 1979; Trüper, 1987; Kondratieva et al., 1992; Castenholz, 2001; Wilmotte \& Herdman, 2001). In phylogenetic trees based on 16S rRNA, 14 major clusters have been identified 
within this phylum; however, it is unclear whether the placement of species within these clusters is evolutionarily meaningful. Also, how these different clusters relate to the major morphological differences within the cyanobacteria is unclear (Wilmotte \& Herdman, 2001). In this context, signature sequences could provide a new and useful means of clarifying taxonomic relationships within this group. In the present work, we have focused mainly on indels that are shared by different cyanobacteria; other indels that were unique to particular cyanobacterial species were not studied further. However, such indels could provide signatures for identifying intermediate-level taxa within the cyanobacterial phylum.

The identification, in the present work, of 14 cyanobacteriaspecific indels in 10 essential and widely distributed proteins provides evidence that the cyanobacterial phylum is monophyletic and that these signatures were probably introduced in a common ancestor of this group. The phylogenetic trees based on various genes/proteins also strongly support this inference. These results also provide evidence that the genes for these proteins have not been laterally exchanged between cyanobacteria and other bacteria, as has been suggested for many other genes (Gogarten et al., 2002; Raymond et al., 2002). If these genes were subjects of lateral gene transfers, the presence of these indels would be expected to be more random, which is clearly not the case here. However, we have previously described a few other signatures that are shared by cyanobacteria and the Deinococcus-Thermus group, and these could be a consequence of lateral gene transfers (Gupta \& Johari, 1998; Gupta, 1998).

The signatures described here are also of value in clarifying the evolutionary relationship between cyanobacteria and plastids (Whatley, 1993; Delwiche et al., 1995; Stiller \& Hall, 1997; Valentin, 1997). For six of these proteins that are also present in plastids (SecA, ADP-Glc-PPase, phytoene synthase, $\mathrm{EF}-\mathrm{Tu}, \mathrm{FtsH}$ and ribosomal $\mathrm{S} 1$ protein), the signatures identified are commonly shared by the plastid homologues. Phylogenetic trees based on some of these proteins show a specific grouping of plastid homologues with cyanobacteria. These results provide additional evidence in support of the endosymbiotic origin of plastids from cyanobacteria (Gray, 1992; Margulis, 1993; Delwiche et al., 1995). However, for three of these proteins, Pol I, inosine-5'-monophosphate dehydrogenase and $\sigma^{70}$, the cyanobacteria-specific indels were not found in eukaryotic homologues. It is possible that these homologues are of either mitochondrial or nuclear-cytosolic origin and would therefore not be expected to contain cyanobacteria-specific signatures (Gupta, 1998). Additional studies are required to clarify this aspect. With the availability of new signatures that allow discrimination between different groups of cyanobacteria, the signature approach could provide important insights into which group of cyanobacteria are the closest relatives of plastid lineages. The functional significance of the identified signatures is not known.
Because these indels have not been lost from any cyanobacteria, they are expected to be functionally important. Hence, studies examining their functional effects should be of much interest.

\section{ACKNOWLEDGEMENTS}

This work was supported by a research grant from the National Science and Engineering Research Council of Canada. We thank Emma Griffiths for many helpful comments and for assistance with this work.

\section{REFERENCES}

Akiyama, Y. (2002). Proton-motive force stimulates the proteolytic activity of FtsH, a membrane-bound ATP-dependent protease in Escherichia coli. Proc Natl Acad Sci U S A 99, 8066-8071.

Armstrong, G. A. (1997). Genetics of eubacterial carotenoid biosynthesis: a colorful tale. Annu Rev Microbiol 51, 629-659.

Barbrook, A. C., Lockhart, P. J. \& Howe, C. J. (1998). Phylogenetic analysis of plastid origins based on secA sequences. Curr Genet 34, 336-341.

Bryant, D. A. (1994). The Molecular Biology of Cyanobacteria. Dordrecht: Kluwer.

Castenholz, R. W. (2001). Phylum BX. Cyanobacteria. Oxygenic photosynthetic bacteria. In Bergey's Manual of Systematic Bacteriology, 2nd edn, vol. 1, pp. 474-487. Edited by D. R. Boone, R. W. Castenholz \& G. M. Garrity. New York: Springer.

Delwiche, C. F., Kuhsel, M. \& Palmer, J. D. (1995). Phylogenetic analysis of tufA sequences indicates a cyanobacterial origin of all plastids. Mol Phylogenet Evol 4, 110-128.

Eisen, J. A. (1995). The RecA protein as a model molecule for molecular systematic studies of bacteria: comparison of trees of RecAs and 16S rRNAs from the same species. J Mol Evol 41, 1105-1123.

Eisen, J. A. \& Hanawalt, P. C. (1999). A phylogenomic study of DNA repair genes, proteins, and processes. Mutat Res 435, 171-213.

Felsenstein, J. (1978). Cases in which parsimony and compatibility methods will be positively misleading. Syst Zool 27, 401-410.

Felsenstein, J. (1994). PHYLIP, version 3.5. Distributed by the author. Department of Genetics, University of Washington, Seattle, USA.

Giovannoni, S. J., Turner, S., Olsen, G. J., Barns, S., Lane, D. J. \& Pace, N. R. (1988). Evolutionary relationships among cyanobacteria and green chloroplasts. J Bacteriol 170, 3584-3592.

Gogarten, J. P., Doolittle, W. F. \& Lawrence, J. G. (2002). Prokaryotic evolution in light of gene transfer. Mol Biol Evol 19, 2226-2238.

Gray, M. W. (1992). The endosymbiont hypothesis revisited. Int Rev Cytol 141, 233-357.

Griffiths, E. \& Gupta, R. S. (2001). The use of signature sequences in different proteins to determine the relative branching order of bacterial divisions: evidence that Fibrobacter diverged at a similar time to Chlamydia and the Cytophaga-Flavobacterium-Bacteroides division. Microbiology 147, 2611-2622.

Griffiths, E. \& Gupta, R. S. (2002). Protein signatures distinctive of chlamydial species: horizontal transfer of cell wall biosynthesis genes $g \operatorname{lm} U$ from archaea to chlamydiae and murA between chlamydiae and Streptomyces. Microbiology 148, 2541-2549.

Gruber, T. M. \& Bryant, D. A. (1997). Molecular systematic studies of eubacteria, using $\sigma^{70}$-type sigma factors of group 1 and group 2 . J Bacteriol 179, 1734-1747. 
Gupta, R. S. (1998). Protein phylogenies and signature sequences: a reappraisal of evolutionary relationships among archaebacteria, eubacteria, and eukaryotes. Microbiol Mol Biol Rev 62, 1435-1491.

Gupta, R. S. (2000). The phylogeny of Proteobacteria: relationships to other eubacterial phyla and eukaryotes. FEMS Microbiol Rev 24, 367-402.

Gupta, R. S. (2001). The branching order and phylogenetic placement of species from completed bacterial genomes, based on conserved indels found in various proteins. Int Microbiol 4, 187-202.

Gupta, R. S. (2002). Phylogeny of bacteria: are we now close to understanding it? ASM News 68, 284-291.

Gupta, R. S. (2003). Evolutionary relationships among photosynthetic bacteria. Photosynth Res 76, 173-183.

Gupta, R. S. \& Griffiths, E. (2002). Critical issues in bacterial phylogenies. Theor Popul Biol 61, 423-434.

Gupta, R. S. \& Johari, V. (1998). Signature sequences in diverse proteins provide evidence of a close evolutionary relationship between the Deinococcus-Thermus group and cyanobacteria. J Mol Evol 46, 716-720.

Gupta, R. S., Bustard, K., Falah, M. \& Singh, D. (1997). Sequencing of heat shock protein 70 (DnaK) homologs from Deinococcus proteolyticus and Thermomicrobium roseum and their integration in a protein-based phylogeny of prokaryotes. J Bacteriol 179, 345-357.

Honda, D., Yokota, A. \& Sugiyama, J. (1999). Detection of seven major evolutionary lineages in cyanobacteria based on the $16 \mathrm{~S}$ rRNA gene sequence analysis with new sequences of five marine Synechococcus strains. J Mol Evol 48, 723-739.

Isono, K., Shimizu, M., Yoshimoto, K., Niwa, Y., Satoh, K., Yokota, A. \& Kobayashi, H. (1997). Leaf-specifically expressed genes for polypeptides destined for chloroplasts with domains of $\sigma^{70}$ factors of bacterial RNA polymerases in Arabidopsis thaliana. Proc Natl Acad Sci U S A 94, 14948-14953.

Kimura, S., Uchiyama, Y., Kasai, N. \& 10 other authors (2002). A novel DNA polymerase homologous to Escherichia coli DNA polymerase I from a higher plant, rice (Oryza sativa L.). Nucleic Acids Res 30, 1585-1592.

Kondratieva, E. N., Pfennig, N. \& Trüper, H. G. (1992). The phototrophic prokaryotes. In The Prokaryotes, pp. 312-330. Edited by A. Balows, H. G. Trüper, M. Dworkin, W. Harder \& K. H. Schleifer. New York: Springer.

Ludwig, W. \& Klenk, H.-P. (2001). Overview: a phylogenetic backbone and taxonomic framework for procaryotic systematics. In Bergey's Manual of Systematic Bacteriology, 2nd edn, vol. 1, pp. 49-65. Edited by D. R. Boone, R. W. Castenholz \& G. M. Garrity. Berlin: Springer.

Margulis, L. (1993). Symbiosis in Cell Evolution. New York: W. H. Freeman.
Morden, C. W., Delwiche, C. F., Kuhsel, M. \& Palmer, J. D. (1992). Gene phylogenies and the endosymbiotic origin of plastids. Biosystems 28, 75-90.

Morse, R., O'Hanlon, K. \& Collins, M. D. (2002). Phylogenetic, amino acid content and indel analyses of the $\beta$ subunit of DNA-dependent RNA polymerase of Gram-positive and Gram-negative bacteria. Int J Syst Evol Microbiol 52, 1477-1484.

Preiss, J. (1996). ADPglucose pyrophosphorylase: basic science and applications in biotechnology. Biotechnol Annu Rev 2, 259-279.

Raymond, J., Zhaxybayeva, O., Gogarten, J. P., Gerdes, S. Y. \& Blankenship, R. E. (2002). Whole-genome analysis of photosynthetic prokaryotes. Science 298, 1616-1620.

Rippka, R., Deruelles, J., Waterbury, J. B., Herdman, M. \& Stanier, R. Y. (1979). Generic assignments, strain histories and properties of pure cultures of cyanobacteria. J Gen Microbiol 111, 1-61.

Schmidt, M. G. \& Kiser, K. B. (1999). SecA: the ubiquitous component of preprotein translocase in prokaryotes. Microbes Infect 1, 993-1004.

Stiller, J. W. \& Hall, B. D. (1997). The origin of red algae: implications for plastid evolution. Proc Natl Acad Sci U S A 94, $4520-4525$.

Subramanian, A. R. (1983). Structure and functions of ribosomal protein S1. Prog Nucleic Acid Res Mol Biol 28, 101-142.

Trüper, H. G. (1987). Phototrophic bacteria (an incoherent group of prokaryotes). A taxonomic versus phylogenetic survey. Microbiologia 3, 71-89.

Turner, S., Pryer, K. M., Miao, V. P. \& Palmer, J. D. (1999). Investigating deep phylogenetic relationships among cyanobacteria and plastids by small subunit rRNA sequence analysis. J Eukaryot Microbiol 46, 327-338.

Valentin, K. (1997). Phylogeny and expression of the secA gene from a chromophytic alga - implications for the evolution of plastids and sec-dependent protein translocation. Curr Genet 32, 300-307.

Viale, A. M., Arakaki, A. K., Soncini, F. C. \& Ferreyra, R. G. (1994), Evolutionary relationships among eubacterial groups as inferred from GroEL (chaperonin) sequence comparisons. Int J Syst Bacteriol 44, 527-533.

Whatley, J. M. (1993). The endosymbiotic origin of chloroplasts. Int Rev Cytol 144, 259-299.

Wilmotte, A. \& Herdman, M. (2001). Phylogenetic relationships among the cyanobacteria based on 16S rRNA sequences. In Bergey's Manual of Systematic Bacteriology, 2nd edn, vol. 1, pp. 487-493. Edited by D. R. Boone, R. W. Castenholz \& G. M. Garrity. New York: Springer.

Woese, C. R. (1987). Bacterial evolution. Microbiol Rev 51, 221-271. 